\title{
Sulfamethoxazole induces zinc changes at hippocampal mossy fiber synapses from pregnant rats
}

\author{
Vanessa N. Corceiro ${ }^{1}$, Fatima C. Bastos ${ }^{1,2}$, Carlos M. Matias ${ }^{2,3}$, Jose C. Dionísio ${ }^{4}$, Rosa M. Santos ${ }^{5}$, \\ Luis M. Rosario ${ }^{5}$, Rosa M. Quinta-Ferreira ${ }^{6}$ and M. Emilia Quinta-Ferreira ${ }^{1,2}$ \\ ${ }^{1}$ Department of Physics, University Coimbra, 3004-516 Coimbra, Portugal \\ ${ }^{2}$ CNC-Center for Neurosciences and Cell Biology, University Coimbra, 3004-504 Coimbra, Portugal \\ ${ }^{3}$ Department of Physics, UTAD, 5000-911 Vila Real, Portugal \\ ${ }^{4}$ Departamento de Biologia Animal, Univ. Lisboa, Lisboa, Portugal \\ ${ }^{5}$ Department of Life Sciences, University Coimbra, 3000-456 Coimbra, Portugal \\ ${ }^{6}$ IEPQPF- Research Centre of Chemical Process Engineering and Forest Products, Department of Chemical Engineering, \\ University Coimbra, Coimbra, Portugal
}

\begin{abstract}
The accumulation of intracellular ionic zinc and pharmaceutical compounds, like the antibiotic sulfamethoxazole, may contribute to various neuropathologies. Sulfamethoxazole and the drug trimethoprim, are inhibitors of enzymes involved in the synthesis of tetrahydrofolate and also of carbonic anhydrases. The inhibition of the latter enzymes, which are localized both intra- and extracellularly and have a key role in $\mathrm{pH}$ regulation, causes alkalinization that is associated with higher spontaneous transmitter release. Intense synaptic stimulation causes the entry of released zinc into postsynaptic neurons, through glutamate receptor channels or voltage dependent calcium channels. The aim of this study was to evaluate the effect of sulfamethoxazole $(180 \mu \mathrm{M})$ on basal postsynaptic zinc and to compare it with that caused by two depolarizing media, containing high potassium or tetraethylammonium, which may induce long term synaptic plasticity. The studies were performed in brain slices from gestating rats, at the mossy fiber synapses from hippocampal CA3 area, using the zinc indicator Newport Green. In the presence of $\mathrm{KCl}(20 \mathrm{mM})$ and sulfamethoxazole $(180 \mu \mathrm{M})$ the zinc signals were enhanced, unlike in tetraethylammonium $(25 \mathrm{mM})$. After sulfamethoxazole the tetraethylammonium evoked zinc signal had reduced amplitude. Thus, the data suggests that sulfamethoxazole enhances transmitter release affecting synaptic zinc physiology.
\end{abstract}

Key words: Sulfamethoxazole — Synaptic zinc — KCl and TEA evoked depolarizations — Newport Green

\section{Introduction}

Antibiotics are frequently used on humans and animals in order to treat various bacterial infections. Disposal of unused pharmaceuticals and by-products is an important source of pharmaceutical pollution, which can affect groundwater and potentially drinking water (Kummerer 2003). The presence of antibiotics in the environment can modify the ecosystems and may favour the development of resistant bacteria (Boreen et al. 2004). The conventional

Correspondence to: Carlos M. Matias, CNC- Center for Neurosciences and Cell Biology, University Coimbra, 3004-504 Coimbra, Portugal E-mail: cmatias@utad.pt wastewater treatments are not designed to remove pharmaceutical waste like antibiotics and therefore they are released in the environment, having been detected in surface waters at concentrations that reach values near $4 \mu \mathrm{M}$ (Heberer 2002). Sulfamethoxazole (SMX) is a widely-used bacteriostatic antibiotic often prescribed along with the antibiotic trimethoprim that interferes with the production of dihydrofolate. SMX is used to treat various infections, such as venereal, gastrointestinal and respiratory infections (Kielhofner 2005). It was observed that about $15 \%$ of the compound is excreted by the human body without being metabolically degraded (Hirsch et al. 1999; Schmitt et al. 2005). This antibiotic has been detected at concentrations of 70-150 ng/l (0.3-0.6 nM) and 200-2000 ng/l (0.8-8 nM) 
in surface water and secondary wastewater effluents, respectively (Dodd and Huang 2004). It has been reported that the application of SMX can be associated, in very rare cases, with encephalopathy and psychosis, essentially in immune-compromised or elderly patients (Saidinejad et al. 2005). The neurotoxic effects result from the excellent penetration in the central nervous system, however, the exact mechanism of neurotoxicity is unknown (Grill and Maganti 2011).

SMX belongs to a generation of antibiotics, that includes the sulfa drugs, which have well known mechanisms of action and inhibit three types of enzymes. Two of them, dihydropteroate synthase and dihydrofolate reductase, are involved in the synthesis of tetrahydrofolate (Caspasso and Supuran 2014). The other type consists of the carbonic anhydrases (CA), found in all living organisms, which catalyze the reaction between carbon dioxide and water resulting in the formation of bicarbonate and protons (Supuran 2008). Thus, they are important intra- and extracellular components of the brain $\mathrm{pH}$ buffering system (Obara et al. 2008; Casey et al. 2010), their inhibitors being clinically used as anticonvulsant drugs (Thiry et al. 2008). It is normally considered that alkalinization causes enhanced neuronal activity and synaptic transmission while acidification leads to lower neuronal response (Sinning and Hubner 2013). Synaptic vesicles become highly acidic during neurotransmitter loading, by the action of the vacuolar $\mathrm{H}^{+}$-ATPase, leading vesicle fusion to the insertion of these proton pumps in the presynaptic membrane (Jefferies et al. 2008). Thus, during synaptic activity, exocytosis involves the release of protons, accompanying transmitter release, causing a short but large acidification of the cleft medium, followed by a long and transient extrasynaptic alkalinization (Sinning and Hubner 2013). In hippocampal synapses, this increase in extracellular $\mathrm{pH}$, that can be up to $0.1-0.2 \mathrm{pH}$ units, may occur in milliseconds. In the case of intense stimulation, and thus higher cellular metabolism, the cleft acidification may last for a longer period. At the Schaffer collaterals-CA1 pyramidal cell synapses, the specific CA inhibitor acetazolamide $(10 \mu \mathrm{M})$, a permeant sulfonamide derivative, causes a large extracellular $\mathrm{pH}$ increase without changes in the corresponding electrophysiological responses, measured as field potentials (Chen and Chesler 1992). In the same work, using an inhibitor of extracellular CA, the membrane impermeant dextran bound sulfonamide (DBSA), similar $\mathrm{pH}$ enhancements were observed, having been proposed that they are due to postsynaptic $\mathrm{H}^{+}$entry through cation channels (Chen and Chesler 1992), following the $\mathrm{pH}$ dependent activation of NMDA receptors (Sinning and Hubner 2013).

At glutamatergic synapses spontaneous transmitter release is diminished at lower intracellular $\mathrm{pH}$, as found in experiments with the $\mathrm{Na}^{+}$-driven $\mathrm{Cl}^{-} / \mathrm{HCO}_{3}{ }^{-}$exchanger Slc4a8, an acid extruder mainly localized to nerve terminals, and is enhanced at higher internal pH (Sinning et al. 2011). On the postsynaptic site, acid extrusion is mediated by the electroneutral $\mathrm{Na}^{+} / \mathrm{HCO}_{3}{ }^{-}$co-transporter Slc4a7, whose expression increases during glutamate excitoxicity (Sinning and Hubner 2013). Since SMX is cell-permeant and inhibits carbonic anhydrases that mediate rapid $\mathrm{pH}$ buffering, its application should cause an increase in intracellular $\mathrm{pH}$ and, consequently, higher glutamate and zinc release.

One of the most important features of the central nervous system is plasticity, which is mainly triggered by specific forms of synaptic activity. In particular, long-term potentiation (LTP), is considered to mediate learning and the formation of cellular memory (Malenka and Bear 2004; Nicoll and Schmitz 2005; Bliss and Collingridge 2013). An important form of LTP is expressed at the zinc enriched mossy fiber-CA3 pyramidal cell synapses, of hippocampal CA3 area, where zinc is co-released with glutamate during synaptic activity (Weiss et al. 2000; Li et al. 2001; Cho et al. 2003; Quinta-Ferreira et al. 2004; Frederickson et al. 2005; Ketterman and Li 2008; Paoletti et al. 2009; Khan et al. 2014). The hippocampal mossy fiber boutons include numerous vesicles that contain high concentrations of free or loosely-bound zinc (Wenzel et al. 1997; Frederickson et al. 2000; Hallermann et al. 2003; Rollenhagen and Lübke 2010). It has been shown that intense zinc release may lead to neurotoxicity and neuronal disorders (Choi and Koh 1998; Frederickson et al. 2005; Sensi et al. 2011) the effect being evoked by zinc entry into neurons through voltagedependent calcium channels (VDCCs) or via AMPA, kainate and NMDA receptor channels (Sensi et al. 1997; Marin et al. 2000). LTP can be evoked by intense electrical or chemical stimulation, in the latter case, through the application of extracellular potassium (Bernard et al. 1994; Roisin et al. 1997), tetraethylammonium (TEA) or 4-aminopyridine (Bancila et al. 2004; Suzuki and Okada 2009). Cell depolarization evoked by external potassium that can stimulate simultaneously all mossy fiber synapses (Zhao et al. 2012), and/or high external zinc, combined or not with potassium, evoked intracellular zinc enhancements in cultured cortical neurons and in hippocampal slices (Sensi et al. 1997; Marin et al. 2000; Ketterman and Li 2008). On the other hand, it has been shown that TEA evokes mossy fiber LTP causing also an inhibition of synaptic activity due to zinc binding to presynaptic $\mathrm{K}_{\mathrm{ATP}}$ channels (Bancila et al. 2004; Suzuki and Okada 2009). Their activation by zinc may lead to cell hyperpolarization and thus to the subsequent reduction of neurotransmitter and zinc discharge, that should result in a decrease of postsynaptic zinc in agreement with our previous observations (Bastos et al. 2017a). With respect to the synaptic action of SMX, there is still no available data. The aim of this work was to investigate the effect of SMX on basal mossy fiber synaptic zinc signals, comparing it with that induced by $\mathrm{KCl}$, and 
also by TEA. For this purpose, we have recorded fluorescence signals from hippocampal slices, obtained from the brain of pregnant gestating rats, with 16 to 18 days of gestation, whose fetuses were used for other experiments. It is well known the existence of numerous adaptations in the mother's brain towards the end of pregnancy gestation, especially in the regions containing the "maternal circuitry" that participates in the control of behavior $(\mathrm{Nu}-$ man 2007). Changes, including a reduction in brain size observed in humans (Oatridge et al. 2002), are also found in other regions like the hippocampus, which is highly involved in memory and learning processes (Koehl and Abrous 2011). It has also been established that pregnancy gestation is associated with various types of structural and functional neuronal changes, leading to altered excitability and plasticity, occurring changes in receptor expression mainly in hormonal systems of maternal regions (Hillerer et al. 2014). In the hippocampus, during pregnancy gestation, the dendritic tree of CA3 pyramidal neurons is less complex (Pawluski et al. 2010), and adult neurogenesis does not seem to be relevant (Hillerer et al. 2014). Although these morphological changes are known, their implications in mossy fiber synaptic transmission have not yet been determined. In previous studies performed at these synapses, using the fluorescent zinc indicator Newport Green, we have measured similar KCl-evoked zinc signals from brain slices of either male, non-gestating of pregnant gestating adult rats. This suggests that mossy fiber synaptic activity is no significantly altered during gestation and that the results of this study are independent of the pregnancy gestation condition.

The optical data was obtained from hippocampal slices containing the zinc selective fluorescent probe Newport Green $(\mathrm{NG})$, which has a moderate affinity for zinc $\left(\mathrm{K}_{\mathrm{D}} \approx 1\right.$ $\mu \mathrm{M})$ and is virtually insensitive to calcium $\left(\mathrm{k}_{\mathrm{D}} \approx 100 \mathrm{mM}\right)$ (Haugland 1996). It was previously shown, in hippocampal slice experiments, that the permeant form of NG reports only postsynaptic zinc changes, because the indicator is hydrolyzed by enzymes in the cytoplasm becoming charged and unable to pass through vesicular membranes (Li et al. 2001). The origin of the signals was confirmed by the fact that they were blocked by the impermeant zinc chelator CaEDTA and by CNQX, an antagonist of the AMPA/Kainate receptor, which blocks synaptic transmission (Li et al. 2001). Thus, since presynaptic zinc is not detected with the permeant form of NG, it is considered that the signals observed with this form of the indicator have a postsynaptic origin (Li et al. 2001). It was observed that the application of SMX $(180 \mu \mathrm{M})$ caused an increase in the basal zinc signals, as observed in the presence of $\mathrm{KCl}$, that is the opposite of the effect due to TEA, that caused a depression. The antibiotic also interfered with the action of TEA, when the two drugs were applied sequentially.

\section{Materials and Methods}

\section{Animals and slices}

All experiments were carried out in accordance with the Directive 2010/63/EU of the European Parliament and Council. All efforts were made to minimize animal suffering and to use only the number of animals necessary to produce reliable scientific data. The experiments were performed in brain slices from Wistar rats, 10 to 13 weeks old, with 16 to 18 days of pregnancy gestation. The brains were from females animals sacrificed used by other research groups, to prepare primary culturesd of cerebrocortical and hippocampal neurons cells from parts of the fetuses. These animals received no pharmaceutical treatment or other intervention before being used in the experiments. Transverse slices, $400 \mu \mathrm{m}$ thick, were taken from the hippocampus.

\section{Solutions}

The hippocampal slices were maintained and tested in artificial cerebrospinal fluid (ACSF) with the following constituents (in mM): $\mathrm{NaCl} \mathrm{124;} \mathrm{KCl} \mathrm{3.5;} \mathrm{NaHCO}_{3} 24$; $\mathrm{NaH}_{2} \mathrm{PO}_{4} 1.25 ; \mathrm{MgCl}_{2} 2 ; \mathrm{CaCl}_{2} 2$ and D-glucose 10, $\mathrm{pH}$ 7.4. The slices were perfused at $1.5-2 \mathrm{ml} / \mathrm{min}$, at a temperature in the range $30-32^{\circ} \mathrm{C}$.

The hippocampal slices were incubated with the permeant form of the Newport Green (NG) indicator $(5 \mu \mathrm{M})$, during 1 hour, at room temperature, being continuously oxygenated $\left(5 \% \mathrm{CO}_{2}\right.$ and $\left.95 \% \mathrm{O}_{2}\right)$. The $\mathrm{NG}$ solution was obtained dissolving $1 \mathrm{mg} \mathrm{NG}$ in $250 \mu \mathrm{l}$ of DMSO and then diluting $5 \mu \mathrm{l}$ of this mixture in $5 \mathrm{ml}$ of ACSF containing $5 \mu \mathrm{l}$ of pluronic acid F-127. The antibiotic SMX was applied at a concentration of $180 \mu \mathrm{M}$, corresponding to the EC50 that causes a 50\% reduction in bacteria bioluminescence (Dantas et al. 2008). The $\mathrm{KCl}$ solution consisted of ACSF with higher concentration of $\mathrm{KCl}, 20 \mathrm{mM}$. The TEA medium applied in some experiments consisted of ACSF containing $25 \mathrm{mM}$ of TEA and higher concentrations of $\mathrm{CaCl}_{2}$ and $\mathrm{KCl}, 10 \mathrm{mM}$ and $5 \mathrm{mM}$, respectively.

\section{Zinc measurements}

The optical signals were measured in an experimental transfluorescence setup based on a microscope (Zeiss Axioskop), including an halogen light source $(12 \mathrm{~V}, 100 \mathrm{~W})$, an excitation narrow band filter ( $480 \mathrm{~nm}, \mathrm{BW} 10 \mathrm{~nm}$ ) and a high pass filter $(>500 \mathrm{~nm})$. The light was collected by a water immersion lens (40×, N.A. 0.75) from hippocampal CA3 area, and then focused on a photodiode (Hammamatsu, $1 \mathrm{~mm}^{2}$ ), passing its signal through a current/voltage converter (I/V), with a $1 \mathrm{G} \Omega$ feedback resistance. The signals were digitally processed by 
means of a 16 bit analog/digital converter, at a frequency of $1.67 \mathrm{~Hz}$, using the Signal Express ${ }^{\mathrm{TM}}$ software from National Instruments. The average value of each group of 100 consecutive points was used for the purpose of illustration, after background correction.

\section{Statistics and materials}

The statistical treatment was performed using the MannWhitney U-test $(p<0.05)$. Drugs used were: NG (Life Technologies Inc.), SMX and TEA (Sigma Aldrich).

\section{Results}

Fluorescence data, considered to have a postsynaptic origin, were obtained from the mossy fiber synapses of hippocampal CA3 area, in slices prepared from the brain of gestating rats previously incubated with the permeant form of the zinc indicator NG. In these synapses extracellular application of $\mathrm{KCl}(20 \mathrm{mM})$, induces a zinc enhancement that is reduced
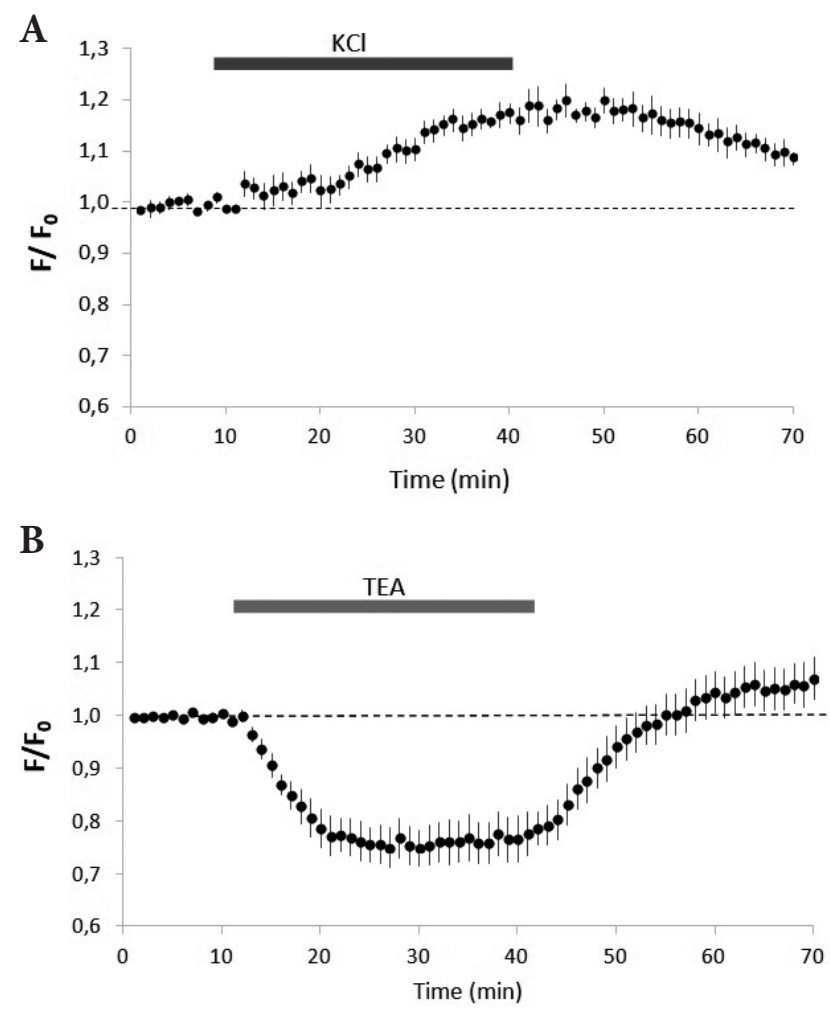

Figure 1. Newport Green zinc signals evoked by depolarizing media. A. Zinc changes induced by $\mathrm{KCl}(20 \mathrm{mM}, n=5)$. B. Zinc signals evoked by tetraethylammonium (TEA) $(25 \mathrm{mM}, n=8)$. The solutions were applied during the period indicated by the bars. The data points represent the average \pm SEM of normalized dye-related fluorescence values. during washout (Fig. 1A). Thus, it can be seen that after an initial period of $10 \mathrm{~min}$ in ACSF, the application of $\mathrm{KCl}$ for 30 minutes caused a $16 \pm 1 \%(n=5)$ increase of the signals with respect to baseline, in the period 35-40 min (Fig. 1A).

Unlike the results obtained with $\mathrm{KCl}$, the zinc signals are reduced in the TEA $(25 \mathrm{mM})$ medium, recovering, upon its removal, to values above the baseline (Fig. 1B). Thus, they are depressed in the presence of TEA and potentiated following its removal. The TEA medium caused a significant decrease in the NG-zinc signals to a steady level that is $23 \pm 4 \%(n=8)$ below the baseline, at 35-40 min. After washout the signals returned to positive values, measuring $7 \pm 2 \%$ above the baseline, in the last 5 minutes of the experiment (Fig. 1B).

The application of the antibiotic SMX $(180 \mu \mathrm{M})$ during a period of 30 minutes caused an increase of the zinc signals, as shown in Fig. 2A. The mean enhancement of the fluorescence signals obtained in the presence of the antibiotic, in
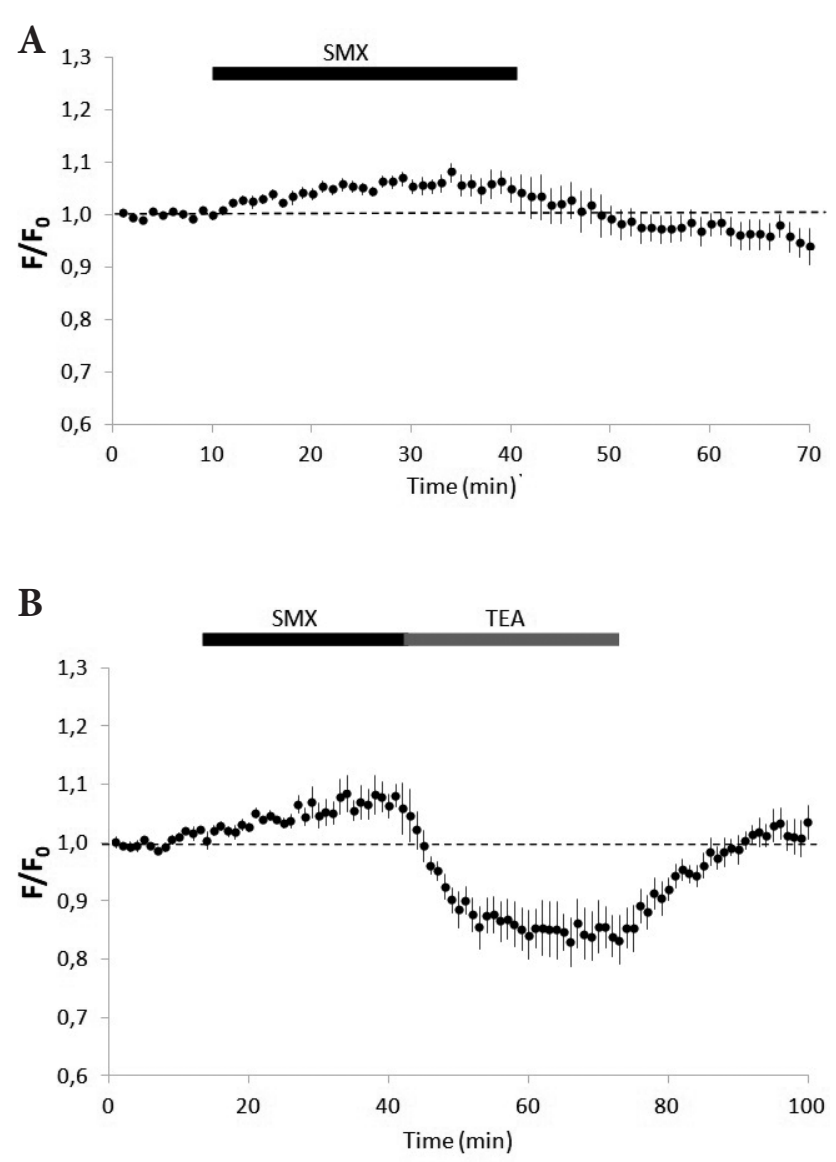

Figure 2. Effect of sulfamethoxazole (SMX) and tetraethylammonium (TEA) on zinc signals from slices incubated with Newport Green. A. Pooled data associated with the application of SMX $(180 \mu \mathrm{M})$, during the period indicated by the bar (until 40 minutes, $n=7$, after that $n=4$ ). B. Zinc changes evoked by SMX followed by the perfusion of the TEA medium $(n=3)$. The solutions were applied at the time intervals indicated by the bars. 
the period $35-40 \mathrm{~min}$, was $6 \pm 2 \%$ of control $(n=7)$. After the removal of SMX the zinc signals decreased to values that are $4 \pm 2 \%$ below the baseline, in the last $5 \mathrm{~min}$. We also tested if SMX affected the zinc changes associated with the formation of chemical TEA-LTP. For that purpose, a TEA (25 mM) containing modified ACSF solution was perfused during $30 \mathrm{~min}$. Following the perfusion with SMX, characterized by increasing signals, the TEA-evoked changes had a different behavior than those registered in the experiments without prior application of the antibiotic (Fig. 2B). Thus it can be observed that the signals had a smaller reduction in the presence of TEA ( $15 \pm 4 \%$ below baseline, $n=3, p<0.05)$ at 65-70 min. In a similar way, after washout of TEA, the potentiation was significantly different from that observed in the experiments performed without previous exposure to SMX ( $3 \pm 2 \%$ of control, $n=3, p<0.05)$ in the interval 95-100 $\mathrm{min}$. An illustration of the mentioned zinc changes, for the different media, is represented by the bar graphs of Figure 3. They suggest that the application of SMX interferes with the consecutive TEA-evoked zinc changes, since these are smaller following the antibiotic (Fig. 2B).

\section{Discussion}

The experiments presented in this work were carried out in brain slices from pregnant gestating animals. For this reason it might be argued that the observed effects are, in total or in part, due to the pregnancy gestation state. Support against this idea comes from studies performed in slices from male Wistar rats, at the same synapses. In these experiments, the application of $\mathrm{KCl}$ evoked a significant zinc potentiation (Li et al. 2001), similar to that we observed using pregnant gestating animals (Bastos et al. 2017b). These observations suggest that the results obtained in the present study, in particular those evoked by SMX, are only due to the action of the applied agents.

The first type of zinc changes observed in this work was evoked by $\mathrm{KCl}(20 \mathrm{mM})$. In the presence of this solution the resting membrane potential becomes depolarized (Bancila et al. 2004), being calculated approximately as $-50 \mathrm{mV}$, under our experimental conditions. Cell depolarization causes the release of glutamate, which induces the opening of postsynaptic membrane receptor channels, such as AMPA, kainate and NMDA and also of L- and T-type VDCCs (Fig. 4). The increase of the zinc signals in the presence of exogenous potassium $(20 \mathrm{mM})$ is thus considered to be due to higher co-released zinc followed by zinc entry into the postsynaptic area, through the mentioned types of receptors and VDCCs (Sensi et al. 1997; Ketterman and Li 2008; Takeda et al. 2009).

The application of TEA $(25 \mathrm{mM})$ gave rise to quite different zinc changes. The TEA-evoked depolarization is known to elicit mossy fiber LTP (Suzuki and Okada 2009). This form of chemical LTP is likely due to the simultaneous activation of a multitude of presynaptic mossy fiber boutons, containing high densities of sodium channels and fast inactivating potassium channels (Geiger and Jonas 2000; Bischofberger et al. 2006), that causes intense glutamate and zinc release. The activation of presynaptic $\mathrm{K}_{\mathrm{ATP}}$ channels by zinc leads to the efflux of potassium and the consequent hyperpolarization of the presynaptic region. This in turn leads to the closing of VDCCs and $\mathrm{K}_{\mathrm{ATP}}$ channels, and to a decrease in presynaptic calcium entry and of glutamate and zinc co-release. This sequence of events explains the observed zinc depression, in agreement with previous findings, from combined LTP and zinc experiments (Bancila et al. 2004; Quinta-Ferreira and Matias 2005; Matias et al. 2010). Upon TEA removal the field potentials become po-
A

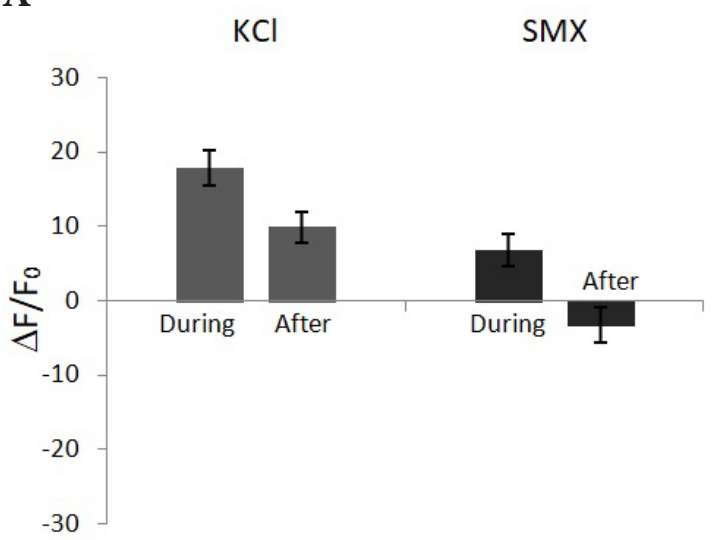

B

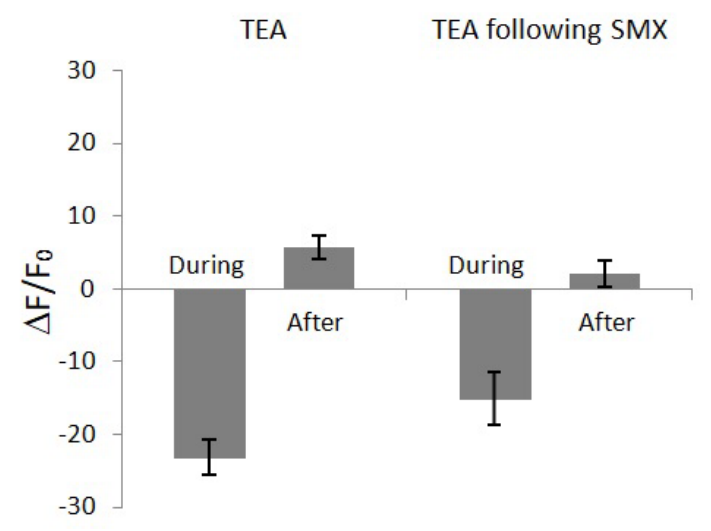

Figure 3. Bar graphs showing the amplitude of the fluorescence signals evoked by $\mathrm{KCl}$, SMX and TEA. Normalized changes during and after the application of $\mathrm{KCl}(20 \mathrm{mM}, n=5)$ and SMX $(180 \mu \mathrm{M}, n=7$ during, $n=4$ after $)(\mathbf{A})$, TEA $(25 \mathrm{mM})$ without $(n=8)$ and with $(n=3)$ prior application of SMX $(180 \mu \mathrm{M})(\mathbf{B})$. The bars represent the mean \pm SEM. 


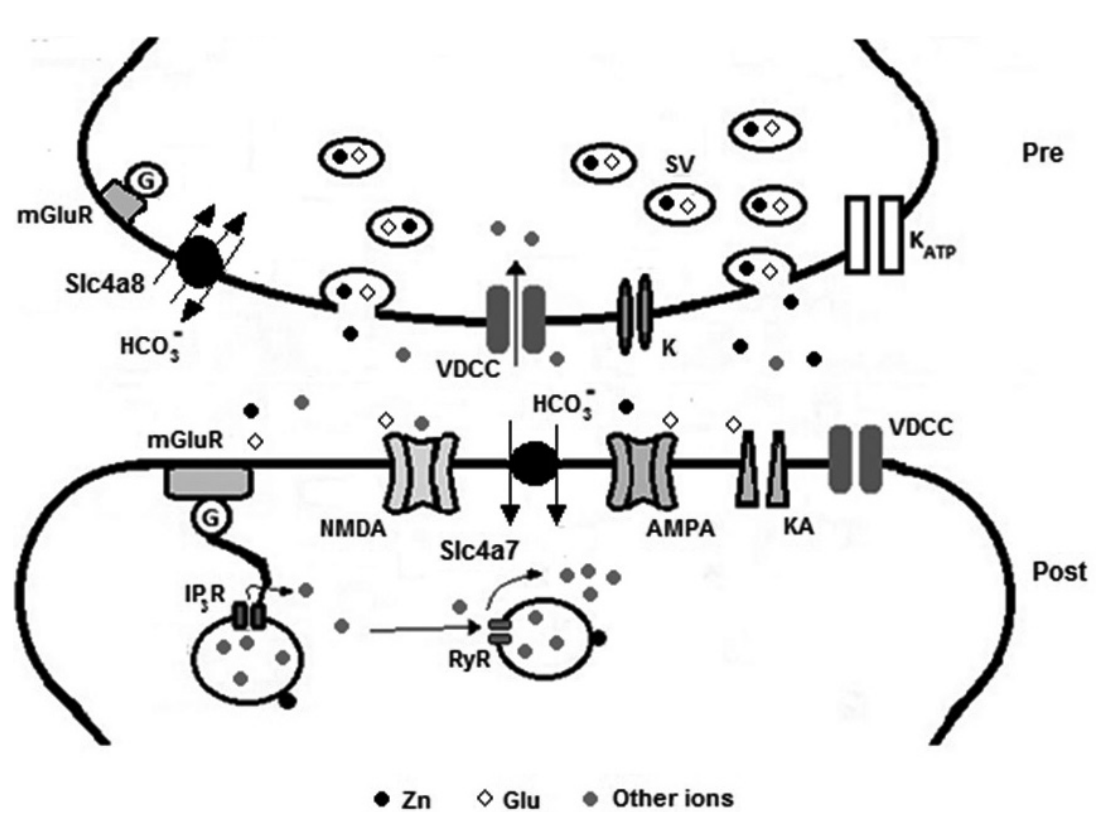

Figure 4. Schematic representation of a hippocampal mossy fiber synapse with pre- and postsynaptic mechanisms. These include synaptic vesicles (SV), ionotropic (NMDA, AMPA, KA) and metabotropic (mGluR) glutamate receptors, voltage-dependent potassium (K) and calcium channels (VDCCs), ATP-sensitive potassium channels $\left(\mathrm{K}_{\mathrm{ATP}}\right)$ and the pre- and postsynaptic $\mathrm{pH}$ regulators Slc4a8 and Slc4a7, respectively. The mGluRs are coupled to $G$ proteins $(G)$ that may activate signalling pathways involving calcium stores containing inositol triphosphate $\left(\mathrm{IP}_{3} \mathrm{R}\right)$ or ryanodine (RyR) receptors. Zinc ions $\left(\mathrm{Zn}^{2+}\right)$ are represented by dark dots, glutamate (Glu) by open diamonds and other ions $\left(\mathrm{Ca}^{2+}, \mathrm{Mg}^{2+}, \mathrm{Na}^{+}\right.$and $\left.\mathrm{K}^{+}\right)$by grey dots.

tentiated, forming TEA LTP, due likely to the initial intense TEA evoked glutamate release (Suzuki and Okada 2009), being a related zinc potentiation observed in this work.

As for the effect of SMX the present results show that this antibiotic caused a rise in postsynaptic zinc, in agreement with the idea that it also evokes an enhancement in glutamate release. This was expected knowing that SMX inhibits carbonic anhydrase enzymes (Caspasso and Supuran 2016), leading to presynaptic alkalinization and thus, higher transmitter release (Sinning and Hubner 2013). Intense co-release of glutamate and zinc and subsequent zinc permeation through postsynaptic receptors and channels (Sensi et al. 1997; Marin et al. 2000; Frederickson et al. 2005), then explain the observed rise in postsynaptic zinc. After washout the zinc signals decrease to values below the baseline, suggesting that the antibiotic alters mossy fiber synaptic physiology. Furthermore, the TEA-induced zinc depression and the subsequent potentiation, formed upon TEA removal, were both affected by prior application of SMX. The observed amplitude reductions suggest that, at the applied concentration, the TEA-evoked postsynaptic zinc changes are sensitive to this antibiotic.

Our data suggest that, at the concentration used, the effect of SMX is not exactly reversible being thus potentially harmful.

There is a multiplicity of causes of neurotoxic activity in the brain, including the formation of reactive oxygen species (Dringen 2000), excessive activation of synaptic glutamate receptors, such as N-methyl-D-Aspartate (NMDA) receptors (Rothman and Olney 1995; Zou and Crews 2005), and influxes to postsynaptic neurons of divalent cations such as calcium (Choi 1998) and zinc (Sensi et al. 1997; Choi and
Koh 1998; Marin et al. 2000). Since excessive zinc influx may play a major role in pathological neuronal activity (Sensi et al. 2011), the measurement of zinc signals using fluorescent indicators is a valuable tool to assess potential toxic agents.

Released zinc can bind to multiple sites existing in preand postsynaptic proteins including glutamate receptors, VDCCs and KATP channels, enhancing or decreasing their conductance (Smart 1989; Bancila et al. 2004) (Fig. 4). Zinc may also form complexes with glutamate and zinc transporters (Colvin et al. 2003) and with cleft constituents such as ATP (Melani et al. 2005). Following intense zinc release, leading to cleft free zinc concentrations in the micromolar range, zinc may enter through the mentioned routes, leading to the type of signals observed.

Despite the large number of studies about neurotoxic effects associated with the use of antibiotics, little is known about the specific neuronal damaging actions of SMX (Grill and Maganti 2011).

From the point of view of clinical implications, only a very small number of severe health cases were associated with neurotoxic effects of SMX (Saidinejad et al. 2005). However, the results of this study reinforce the need to monitor the levels of antibiotics like SMX in both wastewaters and drinking water and also to study their possible pathological effects. It is important to note that, if present in drinking tap water, a very long lasting contamination, e.g. during years, although small, may cause significant neuronal impairment.

Acknowledgements. We thank CNC - Center for Neuroscience and Cell Biology, University of Coimbra, Coimbra, Portugal, for providing the rat brains. Work funded by strategic project UID/ NEU/04539/2013. 


\section{References}

Bancila V, Nikonenko I, Dunant Y, Bloc A (2004): Zinc inhibits glutamate release via activation of pre-synpatic KATP channels and reduces ischaemic damage in rat hippocampus. J. Neurochem. 90, 1243-1250 https://doi.org/10.1111/j.1471-4159.2004.02587.x

Bastos FM, Corceiro VN, Lopes SA, Almeida JG, Matias CM, Dionisio JC, Mendes PJ, Sampaio Dos Aidos FDS, Quinta-Ferreira RM, Quinta-Ferreira ME (2017): Effect of tolbutamide on TEA-induced postsynaptic zinc signals at hippocampal mossy fiber-CA3 synapses. Can. J. Physiol. Pharmacol. 95, 1058-1063 https://doi.org/10.1139/cjpp-2016-0379

Bastos FM, Lopes SA, Corceiro VN, Matias CM, Dionisio JC, Sampaio dos Aidos FD (2017): Postsynaptic zinc potentiation elicited by $\mathrm{KCl}$ depolarization at hippocampal mossy fiber synapses. Gen. Physiol. Biophys. 36, 289-296 https://doi.org/10.4149/gpb_2017001

Bernard J, Lahsaini A, Massicotte G (1994): Potasssium-induced long-term potentiation in area CA1 of the hippocampus involves phospholipase activation. Hippocampus 4, 447-453 https://doi.org/10.1002/hipo.450040407

Bischofberger J, Engel D, Frotscher M, Jonas P (2006): Timing and efficacy of transmitter release at mossy fiber synapses in the hippocampal network. Eur J. Physiol. 453, 361-372 https://doi.org/10.1007/s00424-006-0093-2

Bliss TVP, Collingridge GL (2013): Expression of NMDA receptordependent LTP in the hippocampus: bridging the divide. Molecular Brain 6, 5 https://doi.org/10.1186/1756-6606-6-5

Boreen A, Arnold W, Mcneill K (2004): Photochemical fate of sulfa drugs in the aquatic environment: sulfa drugs containing five-membered heterocyclic groups. Environ. Sci. Technol. 38, 3933-3940 https://doi.org/10.1021/es0353053

Capasso C, Supuran CT (2014): Sulfa and trimethoprim-like drugs - antimetabolites acting as carbonic anhydrase, dihydropteroate synthase and dihydrofolate reductase inhibitors. J. Enzyme Inhib. Med. Chem. 29, 379-387 https://doi.org/10.3109/14756366.2013.787422

Casey J, Grinstein S, Orlowski J (2010): Sensors and regulators of intracellular pH. Nat. Rev. Mol. Cell Biol. 11, 50-61 https://doi.org/10.1038/nrm2820

Chen J, Chesler M (1992): PH transients evoked by excitatory synaptic transmission are increased by inhibition of extracellular carbonic anhydrase. Proc. Natl. Acad. Sci. USA 89, 7786-7790 https://doi.org/10.1073/pnas.89.16.7786

Cho HI, Im J, Kim D, Kim K, Lee J, Han P (2003): Protective effects of extracellular glutathione against $\mathrm{Zn} 2+$-induced cell death in vitro and in vivo. J. Neurosci. Res. 74, 736-743 https://doi.org/10.1002/jnr.10794

Choi DW, Koh JY (1998): Zinc and brain injury. Ann. Rev. Neurosci. 21, 347-375 https://doi.org/10.1146/annurev.neuro.21.1.347

Colvin RA, Fontaine CP, Laskowski M. Thomas D (2003): Zn2+ transporters and $\mathrm{Zn} 2+$ homeostasis in neurons. Eur. J. Pharmacol. 479, 171-185

https://doi.org/10.1016/j.ejphar.2003.08.067
Dantas RF, Contreras S, Sans C, Esplugas S (2008): Sulfamethoxazole abatement by means of ozonation. J. Hazard. Mat. 150, 790-794 https://doi.org/10.1016/j.jhazmat.2007.05.034

Dodd MC, Huang CH (2004): Transformation of the antibacterial agent sufmethoxazole in reactions with chlorine: Kinetics mechanisms, and pathways. Environ. Sci. Technol. 38, $5607-5615$ https://doi.org/10.1021/es035225z

Dringen R (2000): Metabolism and functions of glutathione in brain. Prog. Neurobiol. 62, 649-671 https://doi.org/10.1016/S0301-0082(99)00060-X

Frederickson CJ, Koh JY, Bush AI (2005): The neurobiology of zinc in health and disease. Nat. Rev. Neurosci. 6, 449-462 https://doi.org/10.1038/nrn1671

Frederickson CJ, Suh SW, Silva D, Frederickson CJ, Thompson RB (2000): Importance of zinc in the central nervous system: the zinc-containing neuron. J. Nutr. 130, 1471S-1483S https://doi.org/10.1093/jn/130.5.1471S

Geiger JRP, Jonas P (2000): Dynamic control of presynaptic Ca2+ inflow by fast-inactivating $\mathrm{K}+$ channels in hippocampal mossy fiber boutons. Neuron 28, 927-939 https://doi.org/10.1016/S0896-6273(00)00164-1

Grill M, Maganti RK (2011): Neurotoxic effects associated with antibiotic use: management considerations. Brit. J. Clin. Pharmacol. 72, 381-393 https://doi.org/10.1111/j.1365-2125.2011.03991.x

Hallermann S, Pawlu C, Jonas P, Heckman M (2003): A large pool of releasable vesicles in a cortical glutamatergic synapse. PNAS 100, 8975-8980 https://doi.org/10.1073/pnas.1432836100

Haugland HP(1996): Handbook of Fluorescent Probes and Research Chemicals. (6th ed.). (Ed. Eugene OR), Molecular Probes Inc.

Heberer T (2002): Occurrence, fate, and removal of pharmaceutical residues in the aquatic environment: a review of recent research data. Toxicol. Lett. 131, 5-17 https://doi.org/10.1016/S0378-4274(02)00041-3

Hillerer KM, Jacobs VR, Fischer T, Aigner L (2014): The maternal brain: an organ with peripartal plasticity. Neural Plasticity 2014, ID 574159 https://doi.org/10.1155/2014/574159

Hirsch R, Ternes T, Haberer K, Kratz KL (1999): Occurrence of antibiotics in the aquatic environment. Sci. Total Environ. 225, 109-118 https://doi.org/10.1016/S0048-9697(98)00337-4

Jefferies KC, Cipriano DJ, Forgac M (2008). Function, structure and regulation of the vacuolar $(\mathrm{H}+)$-ATPases. Arch. Biochem. Biophys. 476, 33-42

https://doi.org/10.1016/j.abb.2008.03.025

Ketterman JK, Li YV (2008): Presynaptic evidence for zinc release at the mossy fiber synapse of rat hippocampus. J. Neurosci. Res. 86, 422-434 https://doi.org/10.1002/jnr.21488

Khan M, Goldsmith CR, Huang Z, Georgiou J, Luyben TT, Roder JC, Lippard SJ, Okamoto K (2014). Two-photon imaging of $\mathrm{Zn} 2+$ dynamics in mossy fiber boutons of adult hippocampal slices. Proc. Natl. Acad. Sci. USA 111, 6786-6791 
https://doi.org/10.1073/pnas.1405154111

Kielhofner G (2005): Scholarship and practice: bridging the divide. Am. J. Occup. Ther. 59, 231-239

https://doi.org/10.5014/ajot.59.2.231

Koehl M, Abrous DN (2011): A new chapter in the field of memory: adult hippocampal neurogenesis. Eur. J. Neurosci. 33, 1101-1114 https://doi.org/10.1111/j.1460-9568.2011.07609.x

Kummerer K (2003): Significance of antibiotics in the environment J. Antimicrob. Chemoth. 52, 5-7 https://doi.org/10.1093/jac/dkg293

Li Y, Hough CJ, Suh SW, Sarvey JM, Frederickson CJ (2001): Rapid translocation of $\mathrm{Zn} 2+$ from presynaptic terminals into postsynaptic hippocampal neurons after physiological stimulation. J. Neurophysiol. 86, 2597-2604 https://doi.org/10.1152/jn.2001.86.5.2597

Malenka RC, Bear MF (2004): LTP and LTD: Review an embarrassment of riches. Neuron 44, 5-21 https://doi.org/10.1016/j.neuron.2004.09.012

Marin P, Israël M, Glowinski J, Prémont J (2000): Route of zinc entry in mouse cortical neurons: role in zinc-induced neurotoxicity. Eur. J. Neurosci. 12, 8-18 https://doi.org/10.1046/j.1460-9568.2000.00875.x

Matias CM, Saggau P, Quinta-Ferreira ME (2010): Blockade of presynaptic K ATP channels reduces the zinc-mediated posttetanic depression at hippocampal mossy fiber synapses. Brain Res. 1320, 22-27 https://doi.org/10.1016/j.brainres.2010.01.021

Melani A, Turchi A, Vannucchi M, Cipriani C, Gianfriddo M. Pedata F. (2005): ATP extracellular concentrations are increased in the rat striatum during in vivo ischemia. Neurochem. Int. 47, 442-448 https://doi.org/10.1016/j.neuint.2005.05.014

Nicoll RA, Schmitz D (2005): Synaptic plasticity at hippocampal mossy fibre synapses. Nat. Rev. Neurosci. 6, 863-876 https://doi.org/10.1038/nrn1786

Numan M (2007): Motivational systems and the neural circuitry of maternal behavior in the rat. Dev. Psychobiol. 49, 12-21 https://doi.org/10.1002/dev.20198

Oatridge A, Holdcroft A, Saeed N, Oatridge A, Hajnal JV, Puri BK, Fusi L, Bydder GM (2002): Change in brain size during and after pregnancy: study in healthy women and women with preeclampsia. Am. J. Neuroradiol. 23, 19-26

Obara M, Szeliga M, Albrecht J (2008): Regulation of pH in the mammalian central nervous system under normal and pathological conditions: facts and hypotheses. Neurochem. Int. 52, 905-919 https://doi.org/10.1016/j.neuint.2007.10.015

Paoletti P, Vergano AM, Barbour B, Casado M (2009): Zinc at glutamatergic synapses. J. Neurosci. 158, 126-136 https://doi.org/10.1016/j.neuroscience.2008.01.061

Pawluski JL, Valenca A, Santos AI, Costa-Nunes JP, Steinbusch HW, Strekalova T (2010): Pregnancy or stress decrease complexity of ca3 pyramidal neurons in the hippocampus of adult female rats. Neuroscience 227, 201-210 https://doi.org/10.1016/j.neuroscience.2012.09.059

Quinta-Ferreira ME, Matias CM, Arif M, Dionísio JC (2004): Measurement of presynaptic zinc changes in hippocampal mossy fibers. Brain Res. 1026, 1-10 https://doi.org/10.1016/j.brainres.2004.07.054

Quinta-Ferreira ME, Matias CM (2005): Tetanically released zinc inhibits hippocampal mossy fiber calcium, zinc and synaptic responses. Brain Res. 1047, 1-9

https://doi.org/10.1016/j.brainres.2005.04.006

Roisin MP, Leinekugel X, Tremblay E (1997): Implication of protein kinase $\mathrm{C}$ in mechanisms of potassium-induced longterm potentiation in rat hippocampal slices. Brain Res. 745, 222-230

https://doi.org/10.1016/S0006-8993(96)01155-9

Rollenhagen A, Lübke JHR (2010): The Mossy fiber bouton: the „common" or the "unique“ synapse? Frontiers in Synaptic Neuroscience. 2, article 2

https://doi.org/10.3389/fnsyn.2010.00002

Rothman SM, Olney JW (1995): Excitotoxicity and the NMDA receptor-still lethal after eight years. Trends Neurosci. 18, $57-58$

Saidinejad M, Ewald MB, Shannon MW (2005): Transient psychosis in an immune-competent patient after oral trimethoprimsulfamethoxazole administration. Pediatrics 115, 739-741 https://doi.org/10.1542/peds.2004-1352

Schmitt H, Haapakangas H, Van Beelen P (2005): Effects of antibiotics on soil microorganisms: time and nutrients influence pollution-induced community tolerance. Soil Biol. Biochem. 37, 1882-1892 https://doi.org/10.1016/j.soilbio.2005.02.022

Sensi SL, Canzoniero LMT, Yu SP, Ying HS, Koh JY, Kerchner GA, Choi DW (1997): Measurement of intracellular free zinc in living cortical neurons: routes of entry. J. Neurosci. 17, 9554-9564

Sensi SL, Paoletti P, Koh J, Aizenaman E, Bush AI, Hershfinkel M (2011): The neurophysiology and pathology of brain zinc. J. Neurosci. 9, 16076-16085 https://doi.org/10.1523/JNEUROSCI.3454-11.2011

Sinning A, Liebmann L, Kougioumtzes A, Westermann M, Bruehl C, Hubner CA (2011): Synaptic glutamate release is modulated by the $\mathrm{Na}+$-driven $\mathrm{Cl}$-/HCO3- exchanger Slc4a8. J. Neurosci. 31, 7300-7311 https://doi.org/10.1523/JNEUROSCI.0269-11.2011

Sinning A, Hubner CA (2013): Minireview: $\mathrm{pH}$ and synaptic transmission. FEBS Letters 587, 1923-1928 https://doi.org/10.1016/j.febslet.2013.04.045

Smart TG (1989): Excitatory amino acids: the involvement of second messengers in the signal transduction process. Cell. Mol. Neurobiol. 9, 193-206 https://doi.org/10.1007/BF00713028

Stork C, Li Y (2010): Zinc release from thapsigargin/IP3-sensitive stores in cultured cortical neurons. J. Mol. Signaling 5, 5 https://doi.org/10.1186/1750-2187-5-5

Supuran C (2008): Carbonic anhydrases - an overview. Curr. Pharm. Des. 14, 603-614 https://doi.org/10.2174/138161208783877884

Suzuki E, Okada T (2009): TEA-induced long-term potentiation at hippocampal mossy fiber-CA3 synapses: Characteristics of its induction and expression. Brain Res. 1247, 21-27 https://doi.org/10.1016/j.brainres.2008.09.101

Takeda A, Sakurada N, Ando M, Kanno S, Oku N (2009): Facilitation of zinc influx via AMPA/kainate receptor activation in the hippocampus. Neurochem. Int. 55, 376-382 
https://doi.org/10.1016/j.neuint.2009.04.006

Thiry A, Dogné JM, Supuran CT, Masereel B (2008): Anticonvulsant sulfonamides/sulfamates/sulfamides with carbonic anhydrase inhibitory activity: drug design and mechanism of action. Curr. Pharm. Des. 14, 661-671 https://doi.org/10.2174/138161208783877956

Weiss J, Sensi SL, Koh JY (2000): Zn2+: a novel ionic mediator of neural injury in brain disease. Elsevier Science 21, 395-400 https://doi.org/10.1016/S0165-6147(00)01541-8

Wenzel H, Cole T, Born D, Schwartzkroin P (1997): Ultrastructural localization of zinc transporter-3 (ZnT-3) to synaptic vesicle membranes within mossy fiber boutons in the hippocampus of mouse and monkey. Proc. Natl. Acad. Sci. USA 94, 12676-12681 https://doi.org/10.1073/pnas.94.23.12676

Zhao S, Studer D, Chai X, Graber W, Brose N, Nestel S, Young C, Rodriguez EP, Saetzler K, Frostscher M (2012): Structural plasticity of spines at giant mossy fiber synapses. Front. Neural Circuits 6, 1-7 https://doi.org/10.3389/fncir.2012.00103

Zou JY, Crews FT (2005): TNFa potentiates glutamate neurotoxicity by inhibiting glutamate uptake in organotypic brain slice cultures: neuroprotection by NFkB inhibition. Brain Res. 1034, 11-24

https://doi.org/10.1016/j.brainres.2004.11.014

Received: December 16, 2016

Final version accepted: August 1, 2017 